\title{
Accuracy of the Chula's formula for calculation of standard liver volume in Thai population
}

\author{
Malinee Chuesaard, MD; Natthaporn Tanpowpong, MD* \\ rial Hospital, Bangkok, Thailand.
}

Division of Diagnostic Radiology, Department of Radiology, Faculty of Medicine, Chulalongkorn University, King Chulalongkorn Memo-

\section{Abstract}

Background: Standard liver volume (SLV) is an important concept in living donor liver transplantation for treatment of end-stage liver disease. Accurate estimation of the SLV of living donor and recipient is crucial to ensure optimal graft function and avoid complications.

Objective: 1) to assess the proposed formula for calculation of SLV in
Received: May 24, 2021

Accepted: Jul 02, 2021

Published: Jul 07, 2021

Archived: www.jjgastro.com

Copyright: (C) Tanpowpong N (2021). Thai population, using computed tomography (CT) volumetric measurement as a gold standard. 2) to evaluate the factors (e.g. age, sex, body weight and body surface area) related to differences between SLV calculated from the proposed formula and CT volumetric measurement.

Materials and methods: We evaluated 497 patients underwent contrast-enhanced abdominal multi-detector CT for conditions unrelated to hepatobiliary system with normal liver radiology between October 1 , 2014 and August 31, 2015 were included. Calculated SLV by the proposed formula (SLV = $20.76 \mathrm{x}$ body weight) were compared to the total liver volume (TLV) measured from multi-detector CT by using computerized tool automatically. Factors related to the difference between SLV and TLV were evaluated.

Result: The aforementioned formula showed a high accuracy in estimating the liver volume with some limitations in overweight or underwent patients. The mean difference between SLV and TLV is $3.36 \mathrm{~cm}^{3}$ with SD of $224.65 \mathrm{~cm}^{3}$.

Conclusion: We proposed a new formula ("Chula's standard liver volume") that demonstrates a high accuracy for calculation of SLV in Thai population.

Keywords: Liver volume; MDCT; standard liver volume; Thai population

Abbreviations: SLV: standard liver volume; TLV: total liver volume; MDCT: multi-detector computed tomography; BW: body weight; BMI: body mass index; BSA: body surface area 
Citation: Chuesaard M, Tanpowpong N. Accuracy of the Chula's formula for calculation of standard liver volume in Thai popula-

tion. Japanese J Gastroenterol Res. 2021; 1(2): 1007.

\section{Introduction}

Major hepatic resection and living donor liver transplantation are on the rise for treatment of hepatic malignancy or patients with end-stage liver disease.

Standard liver volume (SLV) represents hepatic metabolic demand of each patient which may correlated with patient's body weight (BW), body mass index (BMI) or body surface area (BSA) $[7,13]$. Accurate estimation of the SLV of living donor and recipient is crucial to ensure optimal graft function and avoid complications such as liver failure in the living donor or graft dysfunction in the recipient [14-17].

There are several methods for liver volume assessment that have been reported in literatures. Tanpowpong et al. revealed that there is an excellent correlation between the measured liver volume using multi-detector computed tomography (MDCT) and actual liver volume measured by water replacement [10]. Many studies also confirmed the accuracy of CT volumetric measurement for liver volume assessment [18-20]. So,CT volumetric measurement has been recently used as a gold standard for liver volume assessment.

Other than the direct CT volumetric measurement of liver, many different formulas for calculating SLV based on body weight or body surface area have been developed in various countries [1-8].

In Thailand, Hatthapornsawan et al. found that SLV correlated well withbody weight [2]. However, the study was examined in 20 autopsied livers without excluding cases with liver disease. Tanpowpong et al. decided to assess the accuracy of all formulas previously reported for SLV calculation and had developed a new formula to predict liver volume based on body weight in Thai population [1]. The suggested formula is SLV $=20.76 \mathrm{x}$ body weight $(\mathrm{kg})$ that was derived from 120 patients, and later recommended to use the proposed formula to calculate SLV.

Even Urata's formula that estimates SLV from BSA in the Japanese population has been widely used.

Therefore, we decided to assess the accuracy of the current proposed "Chula's standard liver volume" formula for calculation of SLV in Thai population, using CT volumetric measurement as a gold standard.

\section{Materials and methods}

This prospective study was approved by our institutional review board. All included patients were provided an informed consent.Sample size of 497 was calculated at power of test $90 \%$ as shown below:

$$
\begin{aligned}
& \alpha=\text { Probability of type I error }=0.05 \\
& Z \alpha=1.645 \\
& \beta=\text { Probability of type II error }=0.1 \text { (Power of the test 90\%) } \\
& Z_{\beta} / 2=1.645
\end{aligned}
$$

$\sigma D=157.0137 ;$ Standard deviation estimated from pilot study

X D = 149.734 ; Mean difference of liver volume between SLV calculated from the formula and using CT volumetric measurement (from pilot study)

$\delta=126.5448 ;$ Acceptable error (data from expert surgeon \& pilot study)

$$
n=\left(\frac{\left(Z_{\alpha}+Z_{\beta / 2}\right) \sigma_{D}}{\delta-\left|\bar{X}_{D}\right|}\right)^{2}=497
$$

\section{Patient selection}

All patients undergoing contrast-enhanced MDCT of the upper or whole abdomen with unrelated hepatobiliary conditions and normal finding of the liver reported by theradiologist between October 1, 2014 and August 31, 2015 were included.

The patients with the following criteria were excluded: underlying hepatobiliary disease, previous surgery of hepatobiliary system, abnormal liver function test, weight loss $>10 \%$ in 3 months, bed ridden, on parenteral nutrition, history of chemotherapy in the past two years, history of abdominal radiation, unavailable MDCT data for measuring total liver volume (TLV) by computer tool at work-station $[1,12]$.

Demographic data were recorded, including gender, age, height, BW, BMI and BSA.

BMI and BSA were calculated by using the formulas as described following;

- Quetelet's formula: BMI = BW(kg)/ Height $(\mathrm{m})^{2}$

- DuBois's formula: BSA $(\mathrm{m} 2)=\mathrm{BW}(\mathrm{kg})^{0.425} \mathrm{x}$ Height $(\mathrm{cm})^{0.725} \mathrm{x}$ 0.00718

\section{Image acquisition and total liver volume measurement}

MDCT was performed using standard protocol by one of the CT scanners as the following; 1) Philips 64: $64 \times 0.625 \mathrm{~mm}$ collimator, pitch $0.797,0.75 \mathrm{sec}$ rotation time, 2) GE healthcare: $64 \times 0.625 \mathrm{~mm}$ collimator, pitch 1.375, $0.5 \mathrm{sec}$ rotation time, 3) Siemens (Somatom sensation 16): $16 \times 0.75 \mathrm{~mm}$ collimator, pitch 1.0, $0.5 \mathrm{sec}$ rotation time, 4) Toshiba (Aquilion one): $80 \times 0.5 \mathrm{~mm}$ collimator, helical pitch $65.0,0.5 \mathrm{sec}$ rotation time.

The portovenous phase MDCT images were transferred to work-station for (TLV) measurement by computer tool (IQQAliver, EDDA Technology). The liver volume was measured by the computer system automatically (Figure 1). TLV was corrected by one researcher and used as the gold standard in this study.

\section{Standard liver volume calculation}

SLV was calculated by using the Chula's formula, which is developed by Tanpowpong et al. based on BW in Thai population. The suggested formula is SLV $=20.76 \times \mathrm{BW}(\mathrm{kg})$. 


\section{Data analysis}

Descriptive statistics were used for age, BW, height, BMI and BSA, shown as mean \pm SD. Paired t-test was used to assess the correlation between calculated SLV from the Chula's standard liver volume formula and TLV measured from MDCT which is considered as a gold standard.

Factors related to differences between SLV and TLV were evaluated by paired t-test, including age, gender, BW, height, BMI and BSA.

Data analyses were performed by using SPSS version 20.0. The statistical significance was considered at $p$-value $<0.05$.

\section{Results}

We included 497 patients, female $55.5 \%$ with mean age = of 52 years (SD 19). The mean (SD) of weight, height, BMI and BSA were $61.0(14.6) \mathrm{kg}, 161.2(0.1) \mathrm{cm}, 23.4$ (4.9) and $1.6(0.2)$ $\mathrm{m}^{2}$, respectively. The indications of $C T$ examination are check up (30.4\%), abdominal pain (26.2\%), infection (17.1\%), KUB disease $(9.3 \%)$, other surgical conditions $(6.2 \%)$, trauma $(4.4 \%)$, post operative complication (3.6\%) and deep vein thrombosis (1.2\%). None of the patients showed any hepatobiliary conditions at CT examination.

The measured TLV using MDCT ranged from 315.96 to 2,674.26 $\mathrm{cm}^{3}$ with mean $(\mathrm{SD})=1,270.16(314.29) \mathrm{cm}^{3}$. The calculated SLV using the Chula's standard liver volume formula ranged from 228.36 to $3,030.96 \mathrm{~cm}^{3}$ with mean $(S D)=1,266.80(302.88) \mathrm{cm}^{3}$. The mean TLV was higher in males than in female, mean (SD) of TLV in male and female are 1,354.02 (335.18) and 1,203.00 (279.48), respectively.

In this study, the current Chula's standard liver volume formula showed high accuracy in calculation of the liver volume, but slightly underestimated the SLV of our patients. The mean difference between SLV and TLV is only $3.36 \mathrm{~cm}^{3}$ with SD of $224.65 \mathrm{~cm}^{3}$. The correlation between SLV and TLV are shown in Figure 2.

The factors related to differences between SLV and TLV are shown in Table 2, SLV overestimated TLV of patients with BW $>80$ or, BSA $>2$ and underestimated TLV of patients with $\mathrm{BMI}<18.5$.

\section{Discussion}

Previous studies showed that liver volume correlates with BW, height, BMI and BSA. Many formulas for calculating SLV have been developed in different populations [1-8]. Most of the existing formulas based on BW or BSA. Previous studies showed that SLV correlated closely with BW in Thai population [1-2,21]. Tanpowpong et al. suggested $\mathrm{SLV}=20.76 \times \mathrm{BW}(\mathrm{kg})$ that was derived from 120 patients. So far, the proposed formula hasn't been widely used by Thai physicians. Therefore, we decided to apply the formula to a larger population with a wider range of patient's age, BW and height to assess the accuracy of the current Chula's standard liver volume formula.

The difference between TLV measured from MDCT and SLV calculated by Chula's standard liver volume formula was approximately $3 \mathrm{~cm}^{3}$ without statistical significance. Similar to Urata's formula (REF) which has been widely used by Thai physicians, the proposed Chula's standard liver volume formula slightly underestimated SLV in Thai population about $3 \mathrm{~cm}^{3}$. The possible explanations for this underestimation are ethnic difference and different applied gold standard [1,9,21]. Most formulas derived from Asian population (i.e., Japanese, Chinese, Indian, and Thai) tend to underestimate SLV while those derived from the Western population tend to overestimate SLV.

In this study, we used CT volumetric measurement as a gold standard by computer tool automatically which provide comparable accuracy and reproducibility as compared to the manual tracing method, but is more efficient [11]. Some limitations of calculated SLV by the proposed formula were noted in patients with extreme age, weight or BMI. This formula tends to underestimate liver volume in young or thin patients, corresponding to Urata's study which included younger patients ( $N=96$, children=65). In contrast, it tends to overestimate liver volume in elderly or overweight patients with statistical significance. However, the number of patients in each aforementioned group were small.

There are some limitations in this study. First, we used TLV measured from MDCT as a gold standard, which shows slightoverestimation from the previous study [21]. However, it has been proven to give sufficient accuracy for assessing liver weight and volume [22]. Furthermore, it is less invasive and more readily available. Second, this study was examined in our single center that may not represent the entire Thai population. However, we included large sample size with a wide range of patients.

\section{Conclusion}

The Chula's standard liver volume formula is proven to give high accuracy in predicting liver volume. Practically it can be used easily, because only body weight is required (SLV $=20.76 \mathrm{x}$ BW). However, some limitations of this formula in overweight or underweight patients are detected.

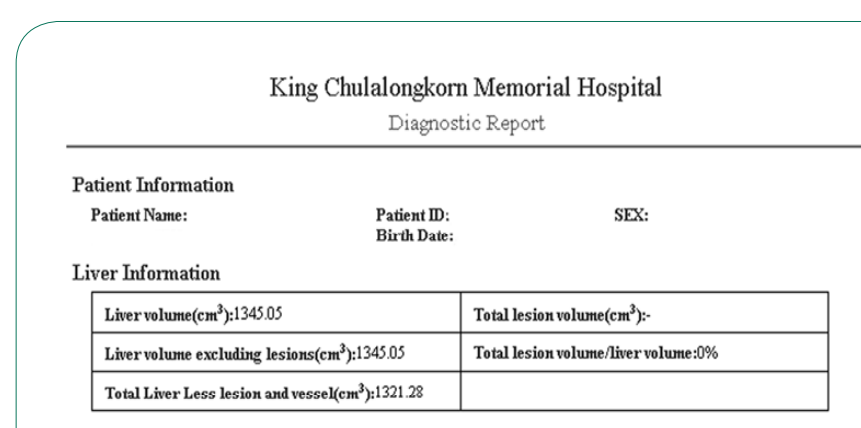

Liver Image
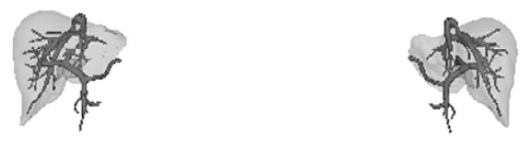

Vein
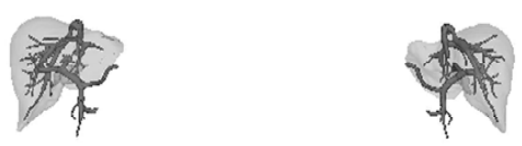

Physiciar's note:

Physician's Name:MC

Date:2/16/2016 11:36:23 AM

Figure 1: Total liver volume measurement using computer tool (IQQA-liver, EDDA Technology). 


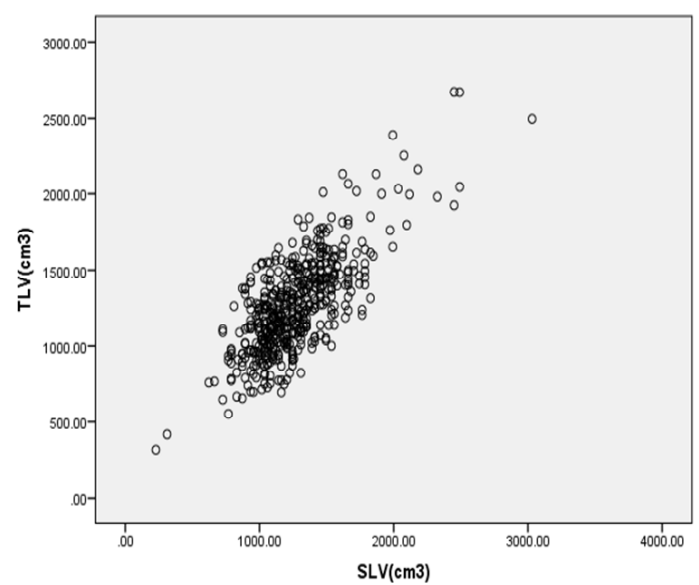

Figure 2: Relationship between calculated standard liver volume and total liver volume.
Table 1: Standard liver volume and total liver volume.

\begin{tabular}{|c|c|c|c|c|}
\hline Gender & Minimum & Maximum & Mean & SD \\
\hline Male (221) & & & & \\
& & & & \\
SLV $\left(\mathrm{cm}^{3}\right)$ & 228.36 & $3,030.96$ & $1,355.32$ & 316.36 \\
$\operatorname{TLV}\left(\mathrm{cm}^{3}\right)$ & 315.96 & $2,674.26$ & $1,354.02$ & 335.18 \\
\hline Female (276) & & & & \\
& & & & \\
SLV $\left(\mathrm{cm}^{3}\right)$ & 311.40 & $2,491.20$ & $1,195.92$ & 272.12 \\
$\operatorname{TLV}\left(\mathrm{cm}^{3}\right)$ & 417.46 & $2,672.64$ & $1,203.00$ & 279.48 \\
\hline Total $(497)$ & & & & \\
& & & & \\
$\operatorname{SLV}\left(\mathrm{cm}^{3}\right)$ & 228.36 & $3,030.96$ & $1,266.80$ & 302.88 \\
$\operatorname{TLV}\left(\mathrm{cm}^{3}\right)$ & 315.96 & $2,674.26$ & $1,270.16$ & 314.29 \\
\hline
\end{tabular}

Table 2: Factors related to the differences between calculated standard liver volume and total liver volume from CT as gold standard.

\begin{tabular}{|c|c|c|c|}
\hline Factors & Number & $\operatorname{TLV}\left(\right.$ mean $\left.\pm S D, \mathrm{~cm}^{3}\right)$ & Differences between mean TLV-SLV \\
\hline Total & 497 & $1,270.2 \pm 314.3$ & 3.4 \\
\hline $\begin{array}{l}\text { Gender } \\
\text { Male } \\
\text { Female }\end{array}$ & $\begin{array}{l}221 \\
276\end{array}$ & $\begin{array}{l}1,354.0 \pm 335.2 \\
1,203.0 \pm 279.5\end{array}$ & $\begin{array}{c}-1.3 \\
7.1\end{array}$ \\
\hline $\begin{array}{c}\text { Age (years) } \\
<20 \\
20-39 \\
40-59 \\
\geq 60\end{array}$ & $\begin{array}{l}31 \\
108 \\
178 \\
180\end{array}$ & $\begin{array}{l}1,205.3 \pm 382.2 \\
1,287.5 \pm 289.1 \\
1,382.4 \pm 334.3 \\
1,159.9 \pm 251.1\end{array}$ & $\begin{array}{r}75.6 \\
35.6 \\
44.3 \\
-68.9\end{array}$ \\
\hline $\begin{array}{c}\text { Body mass inde } \\
\left(\mathrm{kg} / \mathrm{m}^{2}\right) \\
<18.5 \\
18.5-24.9 \\
\geq 25\end{array}$ & $\begin{array}{c}63 \\
286 \\
148\end{array}$ & $\begin{array}{l}1,056.1 \pm 284.4 \\
1,188.6 \pm 228.5 \\
1,518.8 \pm 321.2\end{array}$ & $\begin{array}{c}156.0^{* *} \\
3.2 \\
-61.4 *\end{array}$ \\
\hline $\begin{array}{l}\text { Body surface are } \\
\qquad \begin{array}{c}\left(\mathrm{m}^{2}\right) \\
<1 \\
1-1.9 \\
\geq 2\end{array}\end{array}$ & $\begin{array}{c}2 \\
473 \\
22\end{array}$ & $\begin{array}{c}366.7 \pm 71.8 \\
1,241.4 \pm 265.7 \\
1,971.2 \pm 368.0\end{array}$ & $\begin{array}{c}96.8^{*} \\
9.3 \\
-134.1 *\end{array}$ \\
\hline $\begin{array}{c}\text { Body weight (kg } \\
<40 \\
40-59 \\
60-79 \\
\geq 80\end{array}$ & $\begin{array}{c}19 \\
252 \\
191 \\
35\end{array}$ & $\begin{array}{c}821.3 \pm 234.5 \\
1,132.7 \pm 211.7 \\
1,399.6 \pm 229.4 \\
1,797.3 \pm 392.6\end{array}$ & $\begin{array}{c}110.0^{*} \\
45.8 \\
-30.4 \\
-175.5^{* *}\end{array}$ \\
\hline $\begin{array}{l}\text { Height }(\mathrm{cm}) \\
<150 \\
150-159 \\
160-169 \\
\geq 170\end{array}$ & $\begin{array}{c}49 \\
216 \\
168 \\
64\end{array}$ & $\begin{array}{l}1,065.0 \pm 286.8 \\
1,196.6 \pm 271.5 \\
1,341.0 \pm 306.6 \\
1,489.5 \pm 317.5\end{array}$ & $\begin{array}{c}34.7 \\
6.1 \\
4.2 \\
-32.2\end{array}$ \\
\hline
\end{tabular}

*P-value $<0.05 ; *$ P-value $<0.001$ 


\section{References}

1. Tanpowpong N, Udompornmongkol C. The most appropriate formula for calculation of standard liver volume for Thai population. Asian Biomed. 2012; 6: 227-233.

2. Hatthapornsawan S, Sirivatanauksorn $\mathrm{Y}$, Limsrichamrem S, Waiyawuth W. Standard liver volume in Thai population. Thai J Surg. 2004; 25: 84-86.

3. Urata K, Kawasaki S, Matsunami H, Hashikura Y, Ikegami T, Ishizone $\mathrm{S}$, et al. Calculation of child and adult standard liver volume for liver transplantation. Hepatology. 1995; 21: 1317-1321.

4. Yu HC, You H, Lee H, Jin ZW, Moon JI, Cho BH. Estimation of standard liver volume for liver transplantation in the Korean population. Liver Transplant. 2004; 10: 779-783.

5. Chandramohan A, Eapen A, Govil S, Govil S, Jeyaseelan V. Determining standard liver volume: assessment of existing formulae in Indian population. Indian J Gastroenterol. 2007; 26: 22-25.

6. Li FG, Yan LN, Li B, Zeng Y, Wen TF, Xu MQ, et al. Estimation formula of standard liver volume for Chinese adults. Sichuan Da XueXueBao Yi Xue Ban. 2009; 40: 302-306.

7. Vauthey JN, Abdalla EK, Doherty DA, Gertsch P, Fenstermascher MJ, Loyer EM, et al. Body surface area and body weight predict total liver volume in Western adults. Liver Transpl. 2002; 8: 233240 .

8. Heinemann A, Wischhusen F, Puschel K, Rogiers X. Standard liver volume in the Caucasian population. Liver Transpl Surg. 1999; 5: 366-368.

9. Hashimoto T, Sugawara Y, Tamura S, Hasegawa K, Kishi Y, Kokudo $\mathrm{N}$, et al. Estimation of standard liver volume in Japanese living liver donors. Hepatology. 2006; 21: 1710-1713.

10. Tanpowpong N, Yimpraphan S, Vajragupta L, Sirijindakul B, Nunthasoot B. Accuracy of liver volume measurement using multidetector computed tomography. Asian Biomed. 2007; 1: 415420.

11. Cheng H, Wang X, Li S, Wei G, Zeng X, Chen H, et al. Evaluation of two liver lesion segmentation methods for volume measurement in contrast MDCT. The 22nd international congress on computer assisted radiology and surgery; 2008 Jun 25-28; Barcelona, Spain.

12. Schiano TD, Bodian C, Schwartz ME, Glajchen N, Min AD. Accuracy and significance of computed tomographic scan assessment of hepatic volume in patients undergoing liver transplantation. Transplantation. 2000; 69: 545-550.
13. Kawasaki S, Makuuchi M, Matsunami H, Hashikura Y, Ikegami $\mathrm{T}$, Chisuwa $\mathrm{H}$, et al. Preoperative measurement of segmental liver volume of donors for living related liver transplantation. Hepatology. 1993; 18: 115-120.

14. Yoshizumi T, Taketomi A, Kayashima H, Yonemura Y, Harada N, ljichi $\mathrm{H}$, et al. Estimation of standard liver volume for Japanese adults. Transplant Proc. 2008; 40: 1456-1460.

15. Vauthey JN, Chaoui A, Do KA, Bilimoria MM, Fenstermacher MJ, Charnsangavej $C$, et al. Standardized measurement of the future liver remnant prior to extended liver resection: methodology and clinical associations. Surgery. 2000; 127: 512-519.

16. Kawasaki S, Makuuchi M, Matsunami H, Hashikura Y, Ikegami T, Nakazawa $Y$, et al. Living related liver transplantation in adults. Ann Surg. 1998; 227: 269-274.

17. Nishizaki T, Ikegami T, Hiroshige S, Hashimota K, Uchiyama $\mathrm{H}$, Yoshizumi T, et al. Small graft for living donor related liver transplantation. Ann Surg. 2001; 233: 575-580.

18. Heymsfield SB, Fulenwider T, Nordlinger B, Barlow R, Sones $\mathrm{P}$, Kutner M. Accurate measurement of liver, kidney and spleen volume and mass by computerized axial tomography. Ann Intern Med. 1979; 90: 185-187.

19. Moss AA, Friedman MA, Brito AC. Determination of liver, kidney and spleen volumes by computed tomography: an experimental study in dogs. J Comput Assist Tomogr. 1981; 5: 12-14.

20. Nawaratne S, Fabiny R, Brien JE, Zalcberg J, Cosolo W, Whan A, et al. Accuracy of volume measurement using helical CT. J Comput Assist Tomogr. 1997; 21: 481-486.

21. Tongdee $T$, Keawaen $\mathrm{P}$, Tongdee R. Evaluation of standard liver volume in adult Thai population using CT volumetric measurement. J Med Assoc Thai. 2013; 96: 217-224.

22. Lemke AJ, Brinkmann MJ, Schott T, Niehues SM, Settmacher U, Neuhaus $P$, et al. Living donor right liver lobes: preoperative CT volumetric measurement for calculation of intraoperative weight and volume. Radiology. 2006; 240: 736-742. 